\title{
Translation Strategy of Indonesian Subtitle for English Taboo Words in The Get Hard Movie: Gottlieb's Strategy
}

\author{
Zulfahmi Irwan, Noer Jihad Saleh, Abidin Pammu \\ Faculty of Cultural Sciences - Hasanuddin University, Makassar, South Sulawesi, Indonesia
}

\begin{abstract}
This research aims to find out the emerging translation strategies of Indonesian subtitle for English taboo texts in the Get Hard movie and discover the effect of the translation strategies toward the translation quality. In finding the data, the researcher employs the embedded design, a mixed-methods design, to apply the theory of translation strategy proposed by Gottlieb using a qualitative method and Translation Quality Assessment proposed by House using a quantitative method. There are 6 emerging translation strategies in translating taboo text; 128 Paraphrasing Strategy (43\% or 128 data), Transfer Strategy (25\% or 73 data), Imitation Strategy (4\% or 12 data), Condensation Strategy (26\% or 76 data), Dislocation Strategy (1\% or 3 data), and Transcription Strategy (1\% or 2 data). It means paraphrasing strategy is dominant strategy used by the translator.
\end{abstract}

Keywords: translation, taboo, movie, subtitle, strategy.

\section{INTRODUCTION}

$\mathrm{I}^{\mathrm{n}}$ n common definition, language is defined as a system of communication used by a particular state or community. Language also as a product of culture has convinced that translation might be considered as an ideological activity[1]. In addition, Finocchiaro in Kasmawati Amir [2] describes language as an arbitrary system, vocal symbols which permits all individuals in a given culture to interact or to communicate. In relation to the idea above, it shows that language is absolutely a set of symbols used to communicate one another as well as its function.

As language functions as a tool of communication, Wardaugh[3] explains language as a system of vocal symbols used for human communication. Besides, Wehmeier[4] states language is the system of communication in speech and writing that is used by people of a certain country. From those statements above, it clearly indicates that there is nothing left except language that is used to communicate or to interact one another either by spoken or writing. Based on the language function, people use language to express ideas and feelings. But on the other hand, those who deliver their idea through a certain language should know the things or the standards of that language to avoid misunderstanding in communication and also to convey their idea or information in an appropriate way in order to be understood well. Thus, every language has its own characteristic and standard as well as English.
English is known as an international language that is spoken in all countries. Most people in the world use English to communicate with one another[5]. Therefore, it is the most widely spoken language in the world and it has become the language of the media. Many of the world's biggest news outlets, including newspapers, magazines, radio, and TV are produced in English. Thus, making English is the essential language to be learned and mastered because if people do not, it will rely on translation in comprehending the message and information.

Nowadays, messages and information can be obtained from all kinds of media as well as in literary work. Literary work or art not only serves as entertainment but also knowledge[6]. But people often find there are so many literary works that are quite hard to understand by some readers, especially the readers which have different backgrounds of knowledge and culture. Here is the important role of translation because it not only translates or transfers the text from source language to the target language, but it also assists the readers to get easier in understanding the text by making it readable and suitable with the culture of the target language, because the translation is a procedure of transferring the message starting from source language toward target language[7]. Larson[8], in his book entitled Meaning-Based Translation: A Guide to Cross Language Equivalence describes translation as a change of form from the original language to the target language, but the meaning must also remain the same and awake. In this definition we can know that the translation process is not only limited to changing the form of words, but also has to keep the meaning in order to remain in accordance with the original language.

Some previous studies conducted about translation strategies they are: 1) Yulianita[9] conducted a research entitled: The Acceptability of Religious Terms Translation in the Complete Idiot's Guide to Understanding Islam. This was a descriptive qualitative study with the goal of determining how translation techniques were employed and whether the translation was acceptable. To determine the translation technique, she composed the source language and the target language. The translator utilizes equivalence, borrowing, literal, particularization, generalization, transposition, reduction, addition, explication, and discursive invention, according to the findings of this study. Furthermore, the translation's 
acceptability is rated 2.8 out of 3 on average. It refers to a translation that follows the target text's norms and rules. 2) Aguado[10] conducted research concerning translation entitled: Translation-Strategies Use: A Classroom-Based Examination of Baker's Taxonomy. First, he helped to solve the equivalence problem. Second, he favored translation as a process of mindfulness. Third, He gave pupils the chance to explore and reflect on theoretical concerns that were contextualized. The author of this study wanted to see how English to Spanish translations made by undergraduate university students were used in terms of approach $(n=160)$. Baker's taxonomy has been revised and expanded as a result. Some of the findings suggest that training translation procedures benefits both the quality and accuracy of translation. A debate on strategy selection is also offered.

\section{LITERATURE REVIEW}

\subsection{Translation}

In worldwide communication, translation plays a crucial role. It can serve as a link between people of various languages and cultures. People can learn and understand each other's languages and cultures by using translation. Catford[11] stated that translation is defined as the substitution of equivalent textual material in the target language for textual material in the source language. The goal of translation is to convert the meaning of one language into the comparable meaning of another.

According to Nida and Taber[12], translation is the process of transferring meaning from one language to another using natural counterparts, first in terms of meaning and then in terms of style. Furthermore, Bell[13] gets the same viewpoint, emphasizing meaning and style in the definition of translation. He defined translation as the articulation of a source language in a target language while maintaining semantic and stylistic equivalents.

\subsection{Audiovisual translation}

According to Chiaro[14], the term of "audiovisual translation" refers to the process of transferring the linguistic components of audiovisual works and products from one language to another. Audiovisuals are constructed to be both heard (audio) and seen (visual) simultaneously but they are mainly meant to be seen. Those films or movies, theatrical play, musical opera, web pages, and television programs are just some examples of the large series of audiovisual translation products that people can find and it requires translation.

As audiovisual translation has progressed, some researchers have identified ten distinct types of audiovisual translation. Subtitling and revoicing, on the other hand, can be grouped together. Revoicing is concerned with audiovisual translation procedures with the goal of completely or partially covering the original product's text with the new target language text. As a result, revoicing can be broken down into smaller components of various types. Voice-over or half-dubbing, narration, free commentary, audio description, and dubbing are the several types of dubbing.

Dubbing and subtitling are the two most common forms of audiovisual translation. As the most applied type of revoicing, dubbing is inter-linguistic audiovisual translation which presupposes complete change of the soundtrack of the source language into sound track of the target language with the aim of broadcasting in countries where the original language is not their mother tongue. Diaz Cintaz[15] stated that another significant aspect of dubbing is that it has the same impact on the target language audience as the original audiovisual output. As a result, dubbing is geared toward the target audience, requiring the translator to change the source material to match the requirements of the target language or region.

\subsection{Taboo}

Language is constantly changing as well as culture. As language changes, societies attitudes toward words are considered offensive too. People communicate with others not only about words, but also about language deals with social context and social value. In language, there are certain things that should not be said and when one talks about those things, they talk about in contradictory ways. It is called linguistic taboo. Fairman[16] states linguistic taboo is things which people are not supposed to say. Most civilizations have linguistic taboos, with taboo terms usually being culturespecific and pertaining to physiological functions or religious parts of a culture. Such words are avoided because they are deemed inappropriate and have strong emotional connotations.

Language is built by a variety of non-standard languages and cultural identities. Taboo words are one of the non-standard and cultural identities. Jay[17] defines taboo term as "offensive emotional language", it portrays taboo as immoral and improper. Taboo is a term used by communities to convey their disapproval of particular types of behavior that they perceive to be harmful to their people, either for supernatural reasons or because it violates a moral code. Therefore, taboo is usually found in daily life as Chaim Fershtman et al[18] argued that even though the term taboo was not coined until 1777 , it has always existed in language and society. He also reports the word taboo (from tongan tapu) as signifying approximately forbidden.

Taboo is associated with something that should be avoided, and it is also considered disrespectful to say. Moreover, according to Allan and Burridge[19]: Taboo refers to a social restriction on one's behavior that can cause discomfort, pain, or injury. Taboo refers to activity that is believed to be supernaturally banned or viewed as immoral or wrong. It also refers to action that is restricted or inhibited in an obviously unreasonable manner.

People who believe taboo assume taboo as sacred things which cannot be violated by people in the specific behavior. When someone violates the taboo automatically a bad thing 
would happen to the people who do that. Although people believe in the taboo, actually they do not know the reasons not to do it. No matter what, people still believe that a harmful thing would happen if they do taboo. Furthermore, Allan and Burridge[19] states that taboo as "a proscription behavior that affects everyday life". Then, unless they want to actively violate a taboo, people normally avoid it.

\subsection{Taboo Word}

According to Lindahl[20] taboo words are words that aren't supposed to be stated or used, either because they're considered wrong or immoral, or because they're thought to be supernatural. As people know that there are norms that are created by the members of society itself and that must be paid attention in the society. In human behavior, there are two kinds of taboo, the first one is taboo act and the second one is taboo word. This matter is in line with Fairman[16] who says that in every culture, there are taboo deeds (things you shouldn't do) as well as taboo words (things that you are not supposed to say). In terms of language, taboo refers to things that aren't expressed, particularly words and expressions that aren't used.

Moreover, taboo words may be defined in many ways. Allan and Burridge[21], according to them, taboo words refers to language that consists of so-called "dirty words" and is thus a breach of politeness. It is similar to Wardaugh[3] who states that certain things are not said, not because they cannot be said, but because people do not talk about them or if they are talked about, they are discussed in very roundabout ways. Therefore, before saying something, people have to know which one is allowed and which one is supposed to not be said. In order to make people communicate well in society or community.

Every community has its own reasons why the words are taboo to talk about. However, not all taboo acts could be taboo words, as Fairman[16] says that, some taboo acts have corresponding taboo words, others don't. Moreover, people use taboo to express what they think and show what they feel such as fear, and so on. In addition, Allan[19] states that The term taboo was extended to political and social affairs, and also generalized to the prohibition of the use or practice of anything, particularly an expression of topic or considered offensive. It was extended to political and social affairs, and also generalized to the prohibition of the use or practice of anything, particularly an expression of topic or considered offensive. As a result, social customs discourage or outright prohibit it.

\subsection{Get Hard Movie}

According to Danesi[22], A film is a text that incorporates a series of photographic images that create the illusion of reallife motion and activity. On the other hand, Rabiger[23] stated said that every film is engaging and enjoyable, and it provokes thought in the audience. Furthermore, because each piece of art is distinct and interesting, there are numerous ways to transmit ideas about the real world in a documentary.
Get Hard is a 2015 American film written by Cohen, Jay Martel, and Ian Roberts and directed by Etan Cohen (in his directorial debut). Will Ferrell, Kevin Hart, Tip 'T.I.' Harris, Alison Brie, and Craig T. Nelson feature in the film. The film received mixed reviews when it was released on March 27, 2015 , but it was a commercial success, collecting more than $\$ 111$ million.

Fear of non-consensual buggery, mostly at the hands of looming African-American prisoners with deep voices, drives this film about a car wash manager, Darnell (Kevin Hart), helping a convicted hedge fund manager prepare for a stint in maximum security prison. The story revolves around a wimpy White man's fear of being owned and "turned out" by Black men who treat him like a "bitch," to use a term both characters use frequently. Get Hard movie rated by MPAA (Motion Picture Association of America) with $\mathrm{R}$ or restricted categorization contains a lot of crude and explicit language, some graphic nudity, and drug material. The movie is only for 17 years up and parents are urged to learn more about the movie before taking their young children with them.

\section{STUDY OBJECTIVES}

There are two objectives of study that provide in this research. They are to find out the strategies used by the translator of Get Hard movie in translating taboo text and to figure out the translation quality of taboo texts in translating the English subtitle of Get Hard movie into Indonesia.

\section{METHODOLOGY}

Research design deals with the collection and analysis of variables stated in the problem investigation using a set of techniques and methods. In doing this study, the researcher applied a descriptive and qualitative approach. According to Sugiyono[24] descriptive-qualitative research is employed to obtain an accurate profile of the people, events, or situation. It will be used to explore and describe the taxonomy of translation strategy in translating Taboo texts subtitle into Indonesia by Baker[25].

There were two kinds of data in this study, namely primary data and secondary data. The primary data in this research is the English subtitle of Get Hard movie and its translation. For the secondary data was obtained by using library research. It was done by reading a lot of books, journals, articles, thesis and other materials related to this study, particularly the object of the study. The translation data was assessed by the raters who have the criteria as follows: Willing to participate, understand source and target language (Bahasa and English), and have some experience in translation field.

The researcher collected the data by some procedures presented in chronological as follows: 1) The researcher comprehensively watched the Get Hard movie overall, 2) The researcher determined which part of the movie contains taboo texts by capturing some part of the movie, 3) The researcher writes down the data that are included in taboo texts, 4) The data selected and group into the four taboo texts, and 5) The 
researcher writes down the data and classify the translation strategy used in subtitle

Following the data collection process, the researcher analyzed the information. In order to examine the translation strategies, a number of stages were followed. The first step was to read through all of the data that had been obtained thoroughly. The second step was applying Gottlieb's strategy in order to identify the strategy that occurred in translating the subtitle of the movie. The final step was to draw conclusion from the data analysis.

\subsection{Findings}

\section{FINDING AND DISCUSSION}

The primary goal of this research is to determine the subtitling techniques used in the Indonesian subtitle of Get Hard. Each sentence of the conversation was categorized based on the different sorts of subtitling techniques in order to achieve the goal. The numbers for each method utilized in the Get Hard film are shown in the table below:

Table 1. Each Method Utilized in the Get Hard Movie

\begin{tabular}{|c|c|c|c|}
\hline No & Subtitling Strategy & Frequency & Percentage \\
\hline 1 & Paraphrasing & 128 & $43 \%$ \\
\hline 2 & Transfer & 73 & $25 \%$ \\
\hline 3 & Imitation & 12 & $4 \%$ \\
\hline 4 & Condensation & 76 & $26 \%$ \\
\hline 5 & Dislocation & 3 & $1 \%$ \\
\hline 6 & Transcription & 2 & $1 \%$ \\
\hline
\end{tabular}

\subsection{Discussion}

\subsubsection{Paraphrasing}

To make it simpler for the audience to comprehend what is being subtitled, the subtitler employs paraphrasing. While the subtitlers don't apply the same syntactical rules when subtitling the conversation as they did in the original version of the subtitle, this is referred capabilities. In other words, this technique alters the structure of the subtitles to make them easier for the audience to grasp and read.

Example:

SL: Thank God we won't be needing this anymore.

\section{TL: Syukurlah, kita tidak memerlukan ini lagi.}

\subsubsection{Transfer}

Because the subtitler translates the conversation by exact word, transfer is a method of totally and correctly translating the source material. There is no extra explanation or changing of point of view. Furthermore, by employing this technique, the original text's structure is preserved.

Example:
SL: That you're gonna be somebody's bitch. Ten years of this:

TL: kau akan menjadi pelacur seseorang. 10 tahun dipenuhi hal ini.

\subsubsection{Imitation}

Imitation is a type of imitation in which a person's or place's name or organization is substituted with that of a close cousin. Imitation uses the same forms as the original, usually with the addition of names of people and places.

Example:

SL: Fuck you calling a negro?! - He was. I wasn't.

TL: Siapa yang kau panggil negro?! Dia. Bukan aku.

\section{4) Condensation}

The true purpose of the text must be communicated, rather than omitting superfluous utterances. Condensation reduces the length of a text to eliminate superfluous utterances while maintaining the message's meaning. By adopting the condensation technique, the pragmatic impact might be lost. A brief text's goal is to make it obvious that a message is being conveyed.

Example:

SL: Bitch, you got two seconds to let his fucking pocket go. Two!

TL: Kau punya 2 detik untuk melepaskan sakunya. 2!

\section{5) Dislocation}

The word "dislocation" refers to the employment of special effects in cartoons when the effect's translation is more significant than the substance. The original employs a particular effect in this situation, such as a funny song in a cartoon film where the translated song is less significant than the animation's substance.

Example:

\section{SL: Peter piper picked a peck of pickled cocks!}

\section{TL: Peter piper mengambil beberapa asinan penis!}

\section{6) Transcription}

When a term is uncommon even in the original text, such as when a third language or nonsensical language is employed, transcription is performed.

Example

SL: I'm not a puto

TL: Aku bukan bajingan.

\section{CONCLUSION}

Based on the results of each approach, it can be determined that paraphrase is the most common strategy employed in subtitle translation. The results demonstrate that in order to convert one language into another, translation methods are 
required. If possible, somebody can simply translate the sentence using one of the approaches. Many techniques can be used in a single sentence. In some of the instances, the translator used a variety of translation approaches to ensure that the message was clearly conveyed from the source language to the target language.

\section{REFERENCES}

[1] D. S. Husba, A. Yassi, and N. Saleh, "Translator's Gender and Culture Ideology: A Case Study of the Translation of Eka Kurniawan's Cantik Itu Luka Into Beauty is A Wound,” 2020, doi: 10.4108/eai.15-11-2019.2296441.

[2] K. Amir and S. Azisah, "Gender Analysis on Slang Language in Students Daily Conversation," ETERNAL (English, Teaching, Learn. Res. Journal), vol. 3, no. 2, pp. 221-235, 2017, doi: 10.24252/eternal.v32.2017.a10.

[3] W. Ronald, An Introduction to Sociolinguistics. Cambridge: Blackwell Publishing, 2001.

[4] S. Wehmeier, Oxford Advanced Learner's Dictionary, Oxford: Oxford University Press. 2005.

[5] F. Rahman, "The Constraints of Foreign Learners in Reading English Literary Works: A Case Study at Hasanuddin University," J. Arts Humanit., 2018, doi: 10.18533/journal.v7i2.1327.

[6] F. Rahman, "Cyber Literature: A Reader - Writer Interactivity," Int. J. Soc. Sci. Educ. Stud., vol. 3, no. 4, p. 156, 2017.

[7] M. R. A. Latief, N. J. Saleh, and A. Pammu, "The effectiveness of machine translation to improve the system of translating language on cultural context," IOP Conf. Ser. Earth Environ. Sci., vol. 575, no. 1, 2020, doi: 10.1088/1755-1315/575/1/012178.

[8] D. P. Verity and M. L. Larson, "Meaning-Based Translation: A Guide to Cross-Language Equivalence,” Mod. Lang. J., 1986, doi: $10.2307 / 328112$.

[9] N. G. Yulianita, M. Nababan, and D. Djatmika, "The Acceptability of Religious Terms Translation in the Complete Idiot's Guide to Understanding Islam," Ling. Cult., vol. 12, no. 2, p. 111, 2018, doi: 10.21512/lc.v12i2.3999.
[10] P. Aguado-Giménez and P. F. Pérez-Paredes, "Translationstrategies use: A classroom-based examination of baker's taxonomy," Meta, vol. 50, no. 1, pp. 294-311, 2005, doi: 10.7202/010675ar.

[11] J. Catford, "A Linguistic Theory of Translation." 1965, [Online]. Available: http://books.google.com/books?id=ukUwmgEACAAJ\&pgis=1 .

[12] E. A. Nida and C. R. Taber, "The Theory and Practice of Translation.pdf." p. 216, 1969.

[13] R. T. Bell, Translation and Translating: Theory and Practice. London: Longman, 1991.

[14] D. Chiaro, "Audiovisual Translation," in The encyclopedia of applied linguistics, Blackwell publishing Ltd, 2013.

[15] J. D. Cintas, "New trends in audiovisual translation," New Trends Audiov. Transl., pp. 1-270, 2009, doi: 10.21832/9781847691552.

[16] M. C. Fairman, Fuck. Illinois: Sphinx Publishing, 2009.

[17] T. Jay, "Do Offensive Words Harm People?," Psychol. Public Policy, Law, vol. 15, no. 2, pp. 81-101, 2009, doi: 10.1037/a0015646.

[18] C. Fershtman, U. Gneezy, and M. Hoffman, "Taboos and identity: Considering the unthinkable," Am. Econ. J. Microeconomics, vol. 3, no. 2, pp. 139-164, 2011, doi: 10.1257/mic.3.2.139.

[19] K. Allan and K. Burridge, Forbidden Words; Taboo and the Censoring of Language. New York: Cambridge University Press, 2006.

[20] K. Lindahl, The $\mathrm{x}$-word and its usage: Taboo words and swearwords in general, and $\mathrm{x}$-words in newspapers. Swedia: Karlstads Universitet, 2008.

[21] B. Bachriani, A. H. Yassi, and F. Rahman, "A Comparative Study of Euphemism in English and Buginese: Pragmatic Stylistics Contexts," ELS J. Interdiscip. Stud. Humanit., vol. 1, no. 4, pp. 429-440, 2018, doi: 10.34050/els-jish.v1i4.5760.

[22] M. Danesi, Pesan Tanda Makna. Yogyakarta: Jalasutra, 2010.

[23] M. Rabiger, Directing The Documentary. Oxford: Elseiver, 2009.

[24] Sugiyono. Dr. Prof, Metode Penelitian Kuantitatif, Kualitatif Dan R\&D. Bandung: CV. Alfabeta, 2015.

[25] M. Baker, In Other Words: A Coursebook on Translation. London: Routledge, 1992 